\title{
Scripta
}

\section{La Lucrècia Borja de ficció en el drama d'Hugo i els seus derivats.}

\section{The Victor Hugo's drama Lucrezia Borgia and its derivatives}

\author{
Marc Gomar Calatayud \\ marcgcalatayud@aol.com
}

UNED

\begin{abstract}
Resum: El drama Lucrèce Borgia de Victor Hugo confereix al personatge històric una sèrie d'atributs en sintonia amb el gust sensacionalista de l'època: en ser dona, poderosa, bella i formada. Lucrècia Borja és el millor exemple d'allò que Kristeva anomena «l'abjecte» en les Pouvoirs de l'horreur (1980). Una imatge de femme fatale lligada al verí o l'incest que es popularitzarà gràcies a les nombroses obres derivades del drama: de l'òpera de Donizetti als romanços populars de manera que les característiques del personatge de ficció s'imposaran a l'històric en l'imaginari col lectiu. Lucrècia Borja, que fins aleshores havia estat considerada un instrument al servei de les polítiques familiars, entrarà a formar part per «mèrits» propis del triangle del mal junt amb l germà, Cèsar Borja, i son pare, el papa Alexandre VI.
\end{abstract}

Paraules clau: Lucrècia Borja, Victor Hugo, Gaetano Donizetti, llegenda negra, literatura de cordell, paròdia, segle XIX, Francesc Godó, abjecte

\begin{abstract}
The Victor Hugo's drama Lucrezia Borgia gives to the historical character some attributes in line with the sensationalist preferences of that time: being a female, powerful, beautiful and educated. Lucrezia Borgia is the best example of what Kristeva names «the abject» in Pouvoirs de l'horreur (1980). The character is a femme fatale image linked to poison or incest and it was popularized thanks to the many works resulting from this drama. So that, the features of the fictional character prevailed to the real historical character in the popular beliefs, this happened in Donizetti's opera, but also in the chapbooks of that time. Lucrezia Borgia had previously been considered an instrument in the service for family policies, but she became part of an evil triangle, thanks to her own attitude, along with her brother, Cesare Borgia, and her father, the pope Alexander VI.
\end{abstract}

Keywords: Lucrezia Borgia, Victor Hugo, Gaetano Donizetti, black legend, chapbook, parody, nineteenth century, Francesc Xavier Godó, abject

DATA PRESENTACIÓ: 25/11/2015 ACCEPTACIÓ: 07/12/2015 • PUBLICACIÓ: 26/12/2015

SCRIPTA, Revista internacional de literatura i cultura medieval i moderna, núm. 6 / desembre 2015 / pp. 100 - 119 ISSN: 2340-4841 $\cdot$ doi:10.7203/SCRIPTA.6.7825 


\section{Introducció}

Lucrècia Borja, al servei de la política i les intrigues de son pare, el Papa Alexandre VI, i el seu germà, César Borja, es va veure arrossegada per la llegenda negra familiar. No serà fins al XIx quan passe a formar part, per «mèrits» propis, del triangle diabòlic junt amb son pare i el seu germà. L'estereotip negatiu de Lucrècia Borja, forjat en la política antiborgiana del seu temps, es consagra en el romanticisme del huit-cents i ocasiona a Itàlia i França reaccions apologètiques violentes durant les dècades de major enfrontament ideològic i polític entre el papat i les nacions europees. Entre 1859 i 1869 apareixen nous documents i es publiquen nous títols sobre Lucrècia a Itàlia i també les cartes entre ella i Pietro Bembo.

El drama d'Hugo contribuirà de manera decisiva a crear una imatge de Lucrècia Borja com a heroïna tràgica que es perpetuarà, apuntalada per la d'altres autors com Dumas o Swiburne, al llarg del segle malgrat les reaccions d'historiadors com ara Gilbert o Gregorovius amb escassa influència sobre una opinió pública arrossegada, d'una banda, per l'èxit del drama d'Hugo i l'òpera de Donizetti i, de l'altra, per un personatge històric massa exuberantment mediterrani per a la moral victoriana.

Així doncs, es popularitzen els atributs d'un personatge de ficció que esborra l'històric i, fins i tot, esdevé tema literari. I és que una dona bella, poderosa i preparada reunia totes les condicions per a esdevenir un personatge atractiu per a la ficció del xix. La figura històrica de Lucrècia Borja «va representar bé, en molts àmbits, els papers que tenia assignats» (Shüppert 1994: 53). Podríem dir el mateix sobre el seu paper en les obres de ficció, tot i que es tracta d'una visió esbiaixada que ha contribuit sobre manera a les quatre visions actuals de la filla del papa Alexandre VI:

La d'una figura fàcil de moure en el tauler d'escacs de la història; la d'una bellesa seductora i seduible; la d'una dona amb una irradiació fascinadora o, per contra, amb uns poders diabòlics (Shüppert 1994: 45).

Proposem un recorregut des dels efectes a les causes amb una mostra representativa d'obres entre les quals no hem inclòs, per qüestions d'espai, títols tan suggerents com Lucrecia Borgia. Historia de los crímenes y liviandades de esta célebre cortesana, d'un tal BA, o Lucrecia Borja. Memorias de Satanás, de Manuel González y Fernández.

\section{2. «Botxí amb faldilla»}

Lucręia Borgia (1895), de Francisco Xavier Godó, «estrenada ab brillant éxit en lo Teatro Catalá instalat en lo de Romea la nit del 11 de Janer de 1895» és una «Joguina en un acte escrita en vers català» on el personatge que dóna títol és només una referència temàtica. L'obreta, ambientada en la contemporaneïtat «en una torre dels encontorns de Barcelona», conta com un matrimoni, Pura i Miquel, pren el pèl a un amic, Àngel. Tres personatges de noms immaculats en viu contrast amb les taques que arrossega la que dóna títol a l'obra. 
L'argument és senzill: Àngel està enamorat de Pura, qui li fa creure que enverina el marit per ell. La referència a Lucrècia Borja, el nom de la qual apareix italianitzat, és a dir, desarrelat, apareix en una conversa abans que es produïsquen els fets, quan Àngel confessa que sempre l'ha fascinat Ofèlia per la tendresa,

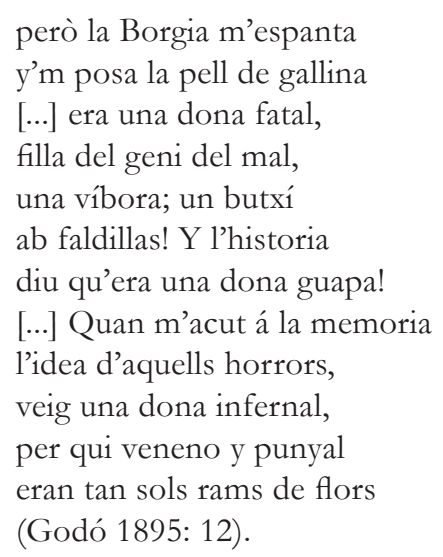

Més enllà d'aportar el qualificatiu de «botxí amb faldilla», Godó manté els tòpics de la Lucrècia Borja bella i perillosa, així com els atributs del verí i el punyal, una imatge presa, òbviament, del drama d'Hugo. De fet, el verí de Miquel també es barreja amb vi; un xerés que beu amb una desmesura exagerada fins que Àngel confessa estupefacte, en un apart, la seua desolació:

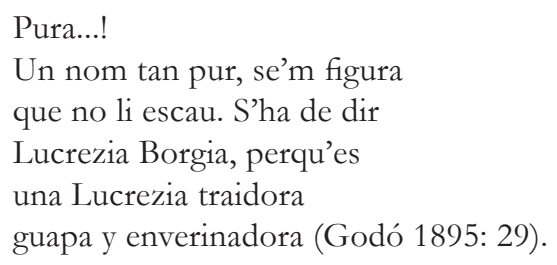

Àngel observa horroritzat del que és capaç Pura i el temor, que no el penediment, li dura fins l'última escena quan el marit, suposadament mort, es posa a menjar com si res perquè es descobrisca l'engany. Pura, en una mena de moralitat, desitja més sort a Àngel la pròxima vegada que s'enamore, i ell respon:

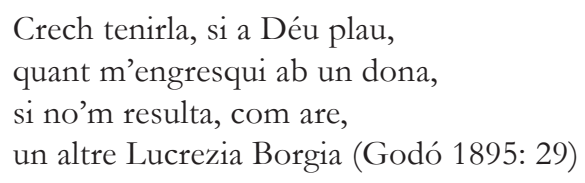


És evident que Godó no va trobar la inspiració en les biografies de William Gilbert (1869) o Ferdinand Gregorovius (1874), per la qual cosa l'hauria de trobar en els escenaris ${ }^{1}$ o en la seua transcripció literària, original ${ }^{2}$ o derivada ${ }^{3}$. Anunciada com a «drama colosal romántico», la Lucrèce Borgia (1833) de Victor Hugo s'havia estrenat a Madrid el 17 de juliol de 1835 al Príncipe i al Montesión de Barcelona el 27 de setembre de 1837. Des de 1838 a 1845 es representa, cada any, en diferents teatres. I, en 1840, coincidirà amb l'òpera de Donizetti, estrenada a Barcelona el 10 de juny. Com veurem en el cas de França, el drama d'Hugo també en va suscitar la paròdia a Espanya: la sarsuela en un acte La venganza de Alifonso, representada en Nadal de 1846 a Madrid i en maig de l'any següent a Barcelona, amb nombroses reposicions.

\section{En la literatura popular espanyola}

Encara en 1859 i 1866 trobem representacions de Lucrèce Borgia com a «drama de aparato» a l'Odeón i el Tirso. Amb tantes i tan variades representacions, la Lucrècia Borja d'Hugo «pasó también a la musa popular» (López de Meneses 1951: 200) en forma de romanç, cançó i novel leta.

Els habitualment anònims plecs de cordell o romanços de cec donen fe de l'enorme difusió de l'obra en terres hispàniques. En el Romance de Lucrecia Borjia, on la peculiar grafia apunta la pronunciació, el gravat en portada ja n'indica el contingut: cinc joves brinden en un banquet en presència de quatre encaputxats que flanquegen la taula amb torxes enceses. Sense cap dubte, el sopar al Palau Negroni del drama d'Hugo. Tot i això, la Biblioteca Nacional data les quatre pàgines entre 1816 i 1852 en coincidència amb els anys d'activitat de la impremta d'Ignacio Estivill, però és evident que és posterior al drama d'Hugo, gràcies al qual podríem acotar la data a partir de 1837, primera representació del drama a Barcelona on es troba la impremta.

El romanç resumeix en 73 estrofes el drama d'Hugo en primera persona. El narrador passeja pels camps de Ferrara quan es troba «un gallardo jóven» que li conta que «Una mujer que parece / ser de la esfera más alta / me escribe incógnitamente» (Anònim 1816/52: 1) i com, després d'adormir-se en el carnaval de Venècia, el desperta «una mujer como un ánjel, / y en cariño extremada» (Anònim 1816/52: 1). És, òbviament, Gennaro, el personatge de ficció que el mateix Hugo adverteix que és una invenció, convertit ací en interlocutor del narrador i testimoni privilegiat dels fets.

1 En la temporada de primavera del Liceu de 1890 figura entre les obres de repertori de la Compañía de Ópera Italiana de Primissimo Cartello.

2 El 1887, la Biblioteca Arte y Letras Daniel Cortezo y C. ${ }^{\text {a }}$ de Barcelona edita Lucrecia Borgia conjuntament amb altres drames d'Hugo (Maria Tudor, La esmeralda, Ruy Blas).

3 Cap al 1880, la impremta barcelonesa Sucesores de Antonio Bosch havia editat la novel leta de 24 pàgines Lucrecia Borgia. Historia de los crímenes y liviandades de esta célebre cortesana. 
El recurs del narrador, sense cap dubte, reforça la versemblança de l'argument d'Hugo: d'entrada, no apareix directament el personatge històric, Lucrècia Borja, sinó el fill, completament producte de la ficció. És més, en un nou gir espectacular, Gennaro morirà en els braços del narrador: «Y calla el infeliz jóven / que ya el aliento le falta / y entre mis brazos espira: / compadeced su desgracia.» (Anònim 1816 / 1852: 4), una al lusió al receptor típica del romanç que també trobem al principi: «Mortales, estadme atentos / y escuchareis la mas rara, / la mas estraña aventura / que ha publicado la fama» (Anònim 1816/52: 1).

El Romance de Lucrecia Borjia la descriu com «ila que aterra al orbe entero / fiera cruel, sanguinaria.» (Anònim 1816/52: 2) amb adjectius com «ufana», «mujer fatal», «enfurecida» o «vengativa». Tot $\mathrm{i}$ això, quan veu Gennaro a punt de morir, perd el color i es mostra «trémula y asustada», una situació que emfatitza la humanitat, almenys maternal, de Lucrècia. En aquest context és on s'emmarca l'ambigüitat de les paraules de Lucrècia durant el banquet final, quan entren els frares cantant $i$ «terrible se muestra diciendo: / ¡Estais en mi propia casa!» (Anònim 1816 / 1852: 4) i explica que «Envenenados estais / y el responso que cantaban / los que presentes están, / era en bien de vuestras almas» (Anònim 1816 / 1852: 4). L’últim vers la caracteritza també com a cínica.

«La historia más rara / os voy a contar» és el que promet l'anònima Canción nueva de la infernal mujer llamada Lucrecia Borgia, duquesa de Ferrara. Cauen en moltes de les (des)qualificacions habituals a partir d'Hugo sense l'atenuant maternal i amb l'agreujant satànic. Ja d'entrada assegura que: «No se conoce en el mundo / monstruo ni fiera peor / que la mujer vengativa / sin rienda, freno ni honon». És la tornada que es repetirà al final de les 19 estances.

L'autor considera els Borja una família italiana «Vil, infame, fiera / objeto de horror; / puñal y venenos / los hacía fuertes / pues dando mil muertes / causaban terron» (López de Meneses 1951: 204). Així doncs, els atributs del punyal i del verí serien famíliars. Ara bé, «Lucrecia, impía / vil sobresalía / en negra crueldad; / parto del infierno / era su alma odiosa, / perversa, viciosa, / llena de maldad [...] al fin les daba / por pasto a Luzbel»» (López de Meneses 1951: 204). Les virtuts satàniques de Lucrècia s'eixamplen respecte a la ficció d'Hugo on a penes trobem que «és com un ducat d'or amb l'efígie de Satanàs» (Hugo 2010:83).

\section{Per què Lucrècia Borja?}

La Lucrèce Borgia d'Hugo és un bon exemple de com en el Romanticisme l'antiga tragèdia clàssica passa a denominar-se «drama». Lucrècia, l'heroïna, suma a la fatalitat del destí la implacable justícia divina que li fa pagar els pecats propis i els familiars en morir a mans del seu fill, Gennaro, qui es veu empés a una situació imprevista que desconeix i sentencia que «sempre arriba el dia que aquesta fatalitat s'acaba gràcies a un últim crim [...] que renta tots els altres» (Hugo 2010: 145). Es tracta d'una lluita inútil contra el destí que ens recorda particularment l'Edip Rei de Sòfocles amb el paral lelisme Lucrècia-Jocasta i Gennaro-Edip, abandonat per sa mare i fruit de l'incest. 
L'elecció del personatge històric no és casual. El XIX és una època de canvis ràpids i massius que alteren el delicat equilibri entre allò correcte i incorrecte, entre el bé i el mal, entre el jo i els altres. Un segle on l'acumulació de capital i propietats no va sempre lligada al compliment dels requisits morals en el qual els avanços científics possibiliten unes altres maneres d'assolir els objectius col lectius.

Diaris, revistes i novel les produeixen noves formes d'escriptura que responen a les expectatives d'un nou públic i s'encarreguen de difondre tant coneixements científics com crims. Els lectors exigeixen detalls i les publicacions barregen realitat i ficció. De Quincey ja comenta les inclinacions voyeurístiques dels seus contemporanis i l'addicció als escàndols en On Murder Considered as One of the Fine Arts (1827). Els mitjans de comunicació presenten als lectors informacions científiques a les quals no hagueren tingut accés d'una altra manera encara que fóra, en molts casos, de manera simplificada, inexacta, o de forma merament especulativa.

A partir de l'interés pels crims i la ciència es popularitza l'enverinament, lligat als descobriments de noves substàncies tòxiques al llarg del segle. No cal perdre de vista que el menorquí Mateu Orfila publica en 1814/1815 el Traité des poisons tirés des regnes minéral, vegetal et animal ou toxicologie générale (1814/15). La química exigeix noves autoritats en l'àmbit de la llei i la justícia i les figures masculines del detectiu, el toxicòleg o el reporter s'enfronten a una realitat que ressuscita la vella associació entre dona i verí que els escriptors del xix plantegen com un desafiament femení a l'ordre simbòlic segons Mittag:

The question of gender evoked in the situation appears interesting in itself. Like with the sublime, (male) subjecthood is challenged by a monstrous unfthomable feminity, which exceeds and negates it (2007).

La curiositat i el terror es presenten amb tota la seua ambivalència. La raó perd l'equilibri i es converteix en violència pura, en una fascinació absoluta per la brutalitat que es traslladarà a les impremtes. No hem d'oblidar, per exemple, que al Regne Unit les execucions són publiques fins al 1868. En diaris, revistes i novel les, els lectors poden experimentar l'agressivitat i la violència sense posar en perill l'ordre establert «or, and that seems to be a more common argument nowadays, if that same reader is taught aggression, murder and violence» (Mittag 2007). És allò que Kristeva (1980) defineix com l'abjecte, «allò que no sóc jo», que pertorba una identitat, un sistema, un ordre econòmic, matern o conjugal. La lògica que defineix el subjecte duta al límit de negar-se a ell mateix produeix l'abjecte, per la qual cosa «allò que no sóc jo» està sotmés també al destí que li marquen la classe, la familia i el gènere.

The fact of its appearance at the edge of the subject, in a zone of abjection, triggers the experience of being one's self Other that motivates so much nineteenth-century literature, whether in Jekyll and Hyde, De Quincey, Swinburne, or countless others (Mittag, 2007)

La llegenda negra dels Borja, dels verins, troba en Lucrècia Borja un model d'abjecte. No és una criminal qualsevol sinó una figura intel ligent, civilitzada i coneguda que qüestiona l'ideal col lectiu. El mitjà d'abjecció, el verí, la dota d'una dimensió sobrehumana perquè, encara que és del «sexe 
dèbil», el coneixement de quantitats i antídots incrementa el poder que té. Els avanços científics han proporcionat sistemes de destrucció cada cop més elaborats que els mitjans de comunicació de l'època difonen i critiquen perquè els consideren amorals; no hem de perdre de vista que en el XIX la culpabilitat i la innocència compten amb una dimensió pública. En aquest sentit, mentre el subjecte seria declarat culpable a l'abjecte se'l considera, senzillament, maleit.

S'enverina per diners, poder o respecte. La invisibilitat del verí està lligada a la invisibilitat de les dones en la vida pública, la seua absència com a subjectes plens en la societat contemporània. La Lucrècia d'Hugo no enverina per diners o per poder, sinó per a fer respectar l'estatus i la família, factors centrals del XIX encara que als Borja se'ls considere endimoniats en associar-los a l'incest, l'assassinat i la corrupció. Hugo se n'aprofita d'això, com adverteix en el pròleg del drama:

\begin{abstract}
Als que li retrauen haver exageratels crims de Lucrècia Borja, els diria: «Llegiu Tomasi, llegiu Guicciardini, llegiu sobre tot el Diarium». Als que, sobre la mort dels martits de Lucrècia, li censuren haver acceptat certs rumors populars i quasi fabulosos, els respondria que, sovint, de les faules del poble naix la veritat del poeta (2010: 40)
\end{abstract}

\title{
5. El drama d'Hugo
}

Hugo planteja el conflicte entre l'enverinadora i la figura idealitzada de la mare on allò matern apareix com l'amenaça mortal i, alhora, la compensació per aquesta amenaça. L'argument gira entorn de la resistència de Lucrècia Borja per a revelar a Gennaro, a qui envia cartes anònimes cada mes, que és fill seu. Quan el veu al Carnaval de Venècia, plora emocionada i s'ha de llevar la màscara per a eixugar-se-les. Com dirà un dels personatges del drama poc després, «Les dones no disfressen el seu cos més que per despullar més ardorosament la seua ànima. Rostre emmascarat, cor nu». (Hugo, 2010: 81). Naix ací el conflicte de la protagonista conscient que Gennaro no acceptaria una mare «criminal». Alhora Gennaro creu que la duquessa s'ha enamorat d'ell i genera un conflicte edípic reforçat per la humiliació pública per part dels seus amics que, després d'arrancar la màscara a Lucrècia i desvelar-ne la identitat, afirmen que és:

\footnotetext{
JEPOO: Incestuosa en tots els graus parentius. Incestuosa amb els seus dos germans, que es van matar entre ells pel seu amor!

SENYORA LuCRĖCIA: Déu meu!

Ascanio: Incestuosa amb el seu pare, el Papa!

SenYora Lucrècia: Tingeu pietat!

Oloferno: Incestuosa amb els seus fills, si n'arribà a tenir, perquè el cel els nega als monstres (Hugo 2010: 71)
}

D'açò darrer podríem deduir, per lògica, que no ho és. En tot cas, els companys de Gennaro l'associen amb accions com «escanyan», «apunyalar», «assassinar», «enverinar», «condemnar a mort» i l'acusen d'«enverinadora», «adúltera» $\mathrm{O}$ «incestuosa»; un assetjament verbal que motivarà la revenja final. 
L'acció se situa en el context històric del Renaixement italià durant el tercer matrimoni de Lucrècia Borja encara que Hugo el considere el quart. No és l'única errada: fets històrics i personatges reals es tergiversen al servei de la trama quan no s'inventen, com ara els crims que la mateixa Lucrècia reconeix:

Jeppo Liveretto, vés a reunir-te amb el teu oncle Vitelli, a qui vaig fer que apunyalaren als soterranis del Vaticà! Ascanio Petrucci, vés a retrobar-te amb el teu cosí Pandolfo, a qui vaig assassinar per robar-li la vila! Oloferno Vitellozzo, el teu oncle t'espera, ja saps qui, Iago d'Appiani, a qui vaig enverinar en una festa! Maffio Orsini, vés a parlar de mi a l'altre món al teu germà de Gravina, a qui vaig fer que escanyaren mentre dormia! Apostolo Gazella, jo vaig fer que decapitaren ton pare, Francisco Fazella, i també vaig fer que degollaren el teu cosí Alfons d'Aragó, i ara et dic a tu, vés-te'n amb ells! (Hugo 2010: 140)

Hugo converteix en amenaça un sil logisme: la història d'Itàlia està lligada als crims dels Borja; els personatges estan lligats a la història d'Itàlia; els personatges moriran en mans d'un Borja. D'entrada, l'obra acusa Lucrècia de tots els mals: des de la pesta i les epidèmies a les forces satàniques, ja que segons Maffio «és com un ducat d’or amb l’efígie de Satanás» (Hugo 2010: 83).

Lucrècia, conscient de la infàmia, es reconeix freda i discreta, «però això naix del meu caràcter, no del meu cor» (Hugo 2010: 99). El seu nom causa horror: «I tot Itàlia m'odia! [...] Jo no vaig nàixer per fer el mal, ara ho sent més que mai. És l'exemple de la meua família el que m’ha dut a la perdició» (Hugo 2010: 57). Una mala reputació de la qual acusa son pare, com també l'acusa del seu caràcter capriciós: «Sóc una dona que no sap què vol. Mon pare em va llançar a perdre, què voleu! Des de la meua infantesa s'han obeït tots els seus desitjos» (Hugo 2010: 98). Per això, no dubtaria a recórrer a la família si calguera: «...em queixaré al papa, em queixaré al del Valentinés, que es troba a Forli amb quinze mil soldats» (Hugo 2010: 93).

Gubetta, confident de Lucrècia, és un dels recursos que usa Hugo per a donar-nos a conéixer la personalitat de la protagonista. En referència als companys de Gennaro reconeix que «Jo en sé molt més que ells, però la senyora Lucrècia en sap més que jo, el duc del Valentinés en sap més que la senyora Lucrècia, i el papa Alexandre VI en sap més que el diable», amb la qual cosa estableix la posició de Lucrècia en la jerarquia borgiana. Lucrècia és causa d'un fratricidi segons Gubetta que no dubta a contar-ho als companys d'armes de Gennaro i, en un apart, al públic.

GubetTA. Jo us ho diré. Cèsar, cardenal de València, va matar Joan, duc de Gandia, perquè tots dos estimaven la mateixa dona.

MAFFIO. I qui era aquesta dona?

GubetTA. (Sempre al fons de l'escenari.) La seua germana.

Jeppo. Prou, senyor de Belverana. No pronuncieu davant de nosaltres el nom d'aquesta dona monstruosa. No hi ha una sola de les nostres famílies en què ella no haja deixat una profunda cicatriu. (Hugo 2010: 53)

En retrobar-se amb el seu fill, Lucrècia sembla que vol redimir-se.

SEnyora Lucrècia. Gubetta, afanya't a escriure al sant pare que jo li demane benevolència per a Pierre Capra! Gubetta, que posen en llibertat Accaioli! I Manfredi de Curzola! I Buondelmonte! I Spadacappa! (Hugo 2010: 58) 
S’avergonyeix per allò que puga pensar Gennaro. I és que Lucrècia se sent: odiada, menyspreada, avorrible, maleïda pels homes, condemnada pel cel, miserable omnipotent [...] Em vull afanyar a redimir el meu passat, a rentar la meua fama, a esborrar les taques que he escampat sobre mi, i a canviar per un pensament de glòria, penitència i de virtut tot el que d'infamant i de sagnant troba Itàlia en el meu nom (Hugo 2010:60)

El de Lucrècia és «abominable [...] palau de luxúria, palau de traïció, palau d'assassinats, palau d'adulteri, palau d'incest, de tota classe de crims» (Hugo 2010:84). Gennaro fa saltar la lletra «B» de l'escut $\mathrm{i}$ «Borgia» es queda en «orgia» en el moment que, segons la genetista Ane Ubersfeld (2001), seria l'epicentre del drama. L'estigma del nom desencadena la ira en un moment decisiu de l'acció que generarà el desig de venjança. En paraules premonitòries Lucrècia afirma que «m'estimaria més morir d'una sola punyalada que mil vegades del mos enverinat del sarcasme i la burla» (Hugo 2010: 92), encara que en assabentar-se que l'autor de l'insult és el seu fill s'enfronta amb el duc i s'oposa al càstig, fet que desencadena la tragèdia.

Entre els coneixements de Lucrècia figuren les lleis. De fet, tipifica l'eliminació de la inicial del cognom: «Es tracta d'un delicte de lesa majestat. Aquests delictes sempre fan caure el cap de qui els trama, i la mà de qui els executa» (Hugo 2010: 94). El càstig pel delicte serveix per a encetar un debat amb el duc en el qual Lucrècia desplega tot els recursos dialèctics que té per aconseguir l'absolució del seu fill mitjançant elogis ${ }^{4}$, metàfores ${ }^{5}$, la lògica ${ }^{6}$, arguments polítics ${ }^{7}$ i, fins i tot, teològics, en un discurs que esdevé una nova reprovació de la seua família: «La misericòrdia, Alfons, això és el que fa que un rei s'assemble a Jesucrist [...] Aquesta pobra Itàlia ja té prou tirans sense nosaltres, des del baró vicari del papa, fins al papa vicari de Déu» (Hugo, 2010: 101). Però l'habilitat dialèctica de Lucrècia no apaivaga la ira del duc:

Conec els vostres mètodes. No em deixaré enverinar com el vostre primer marit, aquells pobre gentilhome d'Espanya del qual ni tan sols conec el nom, ni vós tampoc. No em deixaré caçar com el vostre segon marit, Giovanni Sforza [...] No em deixaré matar a colps de pica, en no importa quina escala, com li passà al tercer, el senyor Alfons d'Aragó (Hugo 2010: 103).

El nombre de matrimonis és una errada repetida en les obres derivades del drama d'Hugo on s'acusa també Lucrècia d'haver enverinat el soldà Zizim, germà de Baiazat. Les acusacions contrasten amb les excepcionals mostres d'amor de mare:

Donaria tota la meua vida per afegir una hora a la teua, vessaria la meua sang per no deixar que vessares una sola llàgrima, m'asseuria al cadafal perquè tu ocupares una trona, pagaria amb

4 «Encara us estime com el primer dia del nostre casori [...] totes les princeses d'Europa m'envejaren per haver-me casat amb el millor cavaller de la cristiandat» (Hugo 2010: 98).

5 «El lleó i la lleona no s’enfadaran per culpa d’un mosquit» (Hugo 2010: 99).

6 «Si aquest jove és qui ha comés sobre la meua persona el delicte de lesa majestat, no pot ser al mateix temps el meu amant» (Hugo 2010: 104).

7 «Ni reis ni nacions podrien viure un sol dia amb la rigidesa de les promeses que es fan» o que la clemència «seria una manera de fer-me apreciar pel poble» (Hugo, 2010:100) 
les tortures de l'infern cadascun dels teus plaers més insignificants, i ho faria sense dubtar-ho, sense segones intencions, i seria feliç, i besaria els teus peus, Gennaro, meu! [...] (Hugo, 2010: 113)

Sola de nou amb Gennaro, que ha enverinat per segona vegada sense voler ${ }^{8}$, reconeix que «he comés actes dolents, sóc un perfecta criminal, i es per això que necessite temps per a reconèixer-ho i penedir-me'n» i busca redimir-se'n:

Aquesta dona faria tot això perquè algun dia li dedicares una mirada de misericòrdia, perquè deixares caure una sola llàgrima sobre les llagues vives del seu cor i de la seua ànima, perquè no li tornares a dir, com acabes de fer amb una veu tan greu que han sonat com el mateix Judici Final: vós sou Lucrècia Borja [...] Vivim tots dos, tu per a perdonar-me, jo per a penedir-me'n (Hugo, 2010: 147)

L'amor maternal contrasta amb la fantasmagòrica aparició al banquet final per anunciar als companys d'armes del fill que han estat enverinats i confessar, perquè augmente el terror, els crims que li havien imputat al principi de l'obra. I és que per a Ledda (2006) la principal convidada al Souper à Ferrare, el primer títol de l'obra, és la mort, introduïda de manera invisible per a aparéixer victoriosa al final. El joc entre allò visible i allò invisible, entre Jekill i Hyde, organitza la peça entorn de la representació de la mort: allò sagrat i allò profà es confonen i el mite esdevé imatge.

La pièce est entièrement conçue autour de la beauté hypnagogique de la femme aux poisons.

Mais l'heroïne d'Hugo est plus que la simple incarnation du mal; elle est une allégorie de la mort capable de franchir les espaces et le temps (Ledda 2006).

Com la mort, Lucrècia també és omnipresent: a Venècia, al palau del duc i al palau Negroni. Un misteri d'encants canviants i ambigus que uneix el dolor amb una paradoxal bellesa que porta Ledda a comparar-la amb Circe: «elles on en commun la vénusté et la science des poisons qui endorment à jamais» (Ledda 2006).

MAFFio. A pesar de tot, la dona és molt bella

JEPPO. És veritat, però hi alguna cosa sinistra que s'oculta sota la seua bellesa (Hugo 2010:83).

Segons Ledda (2006), el que més interessa a Hugo és l'«empoisonneuse a qui l'histoire a inventé une légende» encara que, mitjançant les exageracions de Maffio, semble qüestionar-ho:

Els Borja tenen verins que maten en un dia, en un mes, en un any [...] milloren el vi i fan que buides l'ampolla. Et penses que estàs begut, però estàs mort. O bé, de sobte, et sents llangorós, la pell se t'arruga, els ulls se t'enfonsen, els cabells es tornen blancs, i les dents es trenquen com si foren de vidre [...] El jove té aspecte de vell [...] Es mor i en l'últim moment recorda que fa sis mesos, o un any, va beure un got de vi de Xipre sota el sostre d'un Borja (Hugo 2010: 79).

El paràgraf exemplifica, com hem avançat, l'extraordinària popularitat de la toxicologia en el segle XIx. Com a avanç científic, el poble «té por que els verins que s'hi elaboren dia i nit travessen els murs» (Hugo 2010: 80) i és que és l'arma ideal per al crim perfecte perquè no deixa rastre.

Per a Ledda (2006), el desenllaç de Lucrèce Borgia aconsegueix equilibrar l'ostentació macabra, la música fúnebre i el suspens d'una intriga lineal i senzilla que reforça el final: «la suprême ivresse

8 La primera ho fa a instàncies del marit, en el cas que ens ocupa no comptava que estiguera en el sopar. 
[...] c'est la recontre avec la mort». L'última escena està en la línia dels banquets fatals del Tiestes de Sèneca al Titus Andronicus de Shakespeare. La revista Minerva del 12 de febrer de 1833 dóna testimoni de l'efecte que va causar entre els primers espectadors «La scène tragique du souper interrompue par les chants fúnebres, l'entrée des moines, l'apparition des cercueils et la terrible apostrophe de Lucrèce: "vous êtes tous empoisonnés!” tint la salle haletante» (Ledda: 2006).

«Apareix de sobte, vestida de negre, al llindar de la porta» (Hugo 2010:139). L'aparició fantasmagòrica de Lucrècia constituirà una de les imatges més fortes de l'escena romàntica: «Le spectaculaire de Lucrèce Borgia repose en fait sur la concentration de tous les ressorts dramatiques, mettant en adéquation l'héroïne, ses gestes, l'espace et les sons» (Ledda 2006). Es tracta d'una espectacularitat més a prop de l'òpera i l'al lucinació macabra que del melodrama banal; ens trobem davant d'un drama total construit sobre la desmesura visual i musical: «Une scène envahie progressivament par l'obituaire. Tout prépare au dernier tableau, à cette orgie commuée en banquet de mort» (Ledda 2006).

La música juga un paper decisiu en la tensió dramàtica. De fet, Ledda (2006) assenyala que si l'adaptació operística de Donizetti no va ser tan exitosa és perquè el drama ja incorporava la dimensió lírica de l'obra. Nosaltres, per contra, pensem que això va facilitar l'èxit perquè, a excepció de l'estrena, l’òpera Lucrezia Borgia ho va ser i les 33 representacions al final de temporada demostren el favor del públic i consagren Lucrezia Borgia com una de les òperes més reeixides de Donizetti.

Produïda per a estrenar la temporada de Carnaval de la Scala de Milà de 1933 saltaria el al Her Majesty's Theatre de Londres sis anys després i, en 1942, es traduïria a l'anglés. Les representacions seguirien el 1849 a Hamburg i el 1847, el 1854 i el 1876 a l'Astor Place Opera House de Nova York. L'obra seria produïda de nou el 1884 a l'Academy of Music i el 1902 al Metropolitan Opera amb Enrico Caruso en el paper de Gennaro, i es portaria a escena regularment fins a consolidar-se en el repertori amb la representació, el 24 d'abril de 1993, al Maggio Musicale Fiorentino.

\section{L’òpera de Donizetti}

L'adaptació operística en suavitza l'argument, però no el suficient com per a evitar la censura en algunes ciutats italianes $\mathrm{o}$, fins $\mathrm{i}$ tot, per a haver de canviar el nom de la protagonista $\mathrm{i}$ el context històric per a poder-la representar. Així que Romani, el llibretista, s’havia avançat a algunes de les possibles objeccions de la censura: mentre que, en l'obra d'Hugo, Gennaro és el fruit d'una relació incestuosa entre Lucrecia i el seu germà Joan, en el llibret de Romani no s'esmenta el pare del fill amb la qual cosa la il legitimitat roman, però l'incest desapareix. A diferència del drama l'òpera evita el matricidi: Gennaro no apunyala Lucrècia, però mor enverinat per ella. En resum: lliura del crim al personatge de ficció, però no al que compta amb significació històrica amb la qual cosa es 
pot afirmar que «La obra lírica contribuyó a hacer de Lucrecia la primera verdadera heroína de los Borgia» (Le Thiec, 2012: 29).

Com el drama és una obra de contrastos entre l'alegria desenfadada del principi carnavalesc i el terror d'estil Allan Poe del final tètric; entre el brindis alegre de taverna d'Orsini i l'horror gòtic del rèquiem amb tocs fúnebres de campanes. Malgrat que la gelosia infundada d'Alfonso sembla empentar l'argument cap al tradicional triangle amorós, Donizetti hi introdueix una sèrie d'innovacions notables i desplaça una història d'amor convencional gràcies als tocs il lícits que aporten les relacions sentimentals de Gennaro: d'una banda, la instintiva i fervorosa que manté amb Lucrècia que ratlla l'incest; de l'altra, la d'implicacions homoeròtiques amb el seu amic Orsini. L'adaptació operística emfatitza l'ambient d'aparences disfressades, d'identitats incertes, d'intriga i de l'ambigüitat nocturna subjacent al drama.

Lucrècia destaca des de la mateixa distribució de veus, totes masculines a excepció de la d'Orsini, que interpreta una contralt, i la seua, soprano, que destaca en aguts sobre la resta. A més, enfront dels perfils plans de Gennaro i el duc Lucrècia és el caràcter psicològicament més complex. Monstre i mare alhora és capaç de generar repulsió i simpatia. «Victor Hugo, in blending vice and virtue to form her character, created a part for a great actress, and it requires a great singing-actress» (Commons 1977: 6), un paper excepcional per a una prima donna.

Es tracta d'una Lucrècia més decidida que la d'Hugo i que confessa abans a Gennaro que és sa mare. Tampoc mor apunyalada pel fill; es desmaia ${ }^{9}$. Una Lucrècia, doncs, més humana, que plora amb més facilitat, s'expressa menys fredament i no s'atreveix a llevar-se la màscara atemorida per la mala fama que arrossega.

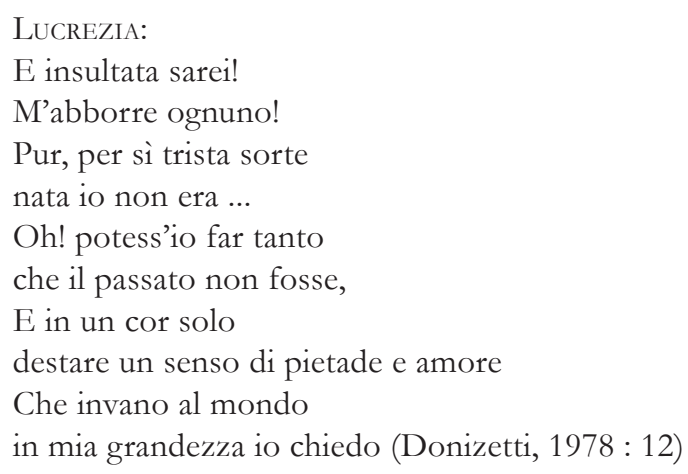

Només la visió del fill adormit l'anima a llevar-se la màscara, a redimir-se. Podríem dir que, mentre els criminals oculten la seua identitat, les mares donen la cara. Però l'amor maternal, apassionat i

9 És l'última òpera que va cantar Thérèse Tietjens al Her Majesty's Theatre de Londres en 1877. Malalta de càncer, va caure en l'última escena i moriria poc després. El teló es va alçar dues vegades a causa l'aplaudiment amb Tietjens, qui jeia immòbil i inconscient a l'escenari. 
inconfessable, dóna peu a la gelosia del marit. Lucrècia demana al duc que no mate Gennaro, fins $\mathrm{i}$ tot perdona l'ofensa de transformar «Borgia» en «Orgia». Apel la a la clemència com una de les majors virtuts del governant. I com a últim recurs apel la amb una amenaça a la família:

Don Alfonso mio quarto marito!

Omai troppo m'hai visto piangente,

Omai troppo il mio core è ferito.

Al dolore sottentra la rabbia,

Ti potria far la Borgia pentir (Donizetti 1978: 20).

La Lucrècia que ho donaria tot pel fill contrasta amb la descripció que ofereixen els companys de Gennaro. Segons Orsini, odiada i temuda, «donna che infame si rese, che l'orrore sarà d'ogni etade [...] donna venefica, impura, vilipese, oltraggiò la natura» (Donizetti, 1978:15). I no dubten a recriminar els seus crims en públic:

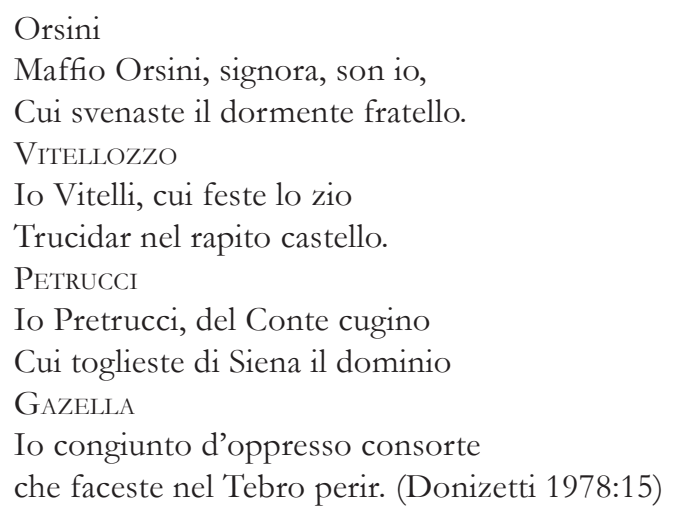

Tots els qualificatius se sintetitzen en la definició més usada per a referir-se a ella: «È la Borgia!». Ja ens l'havia presentada així Liverotto en començar l'obra: «La Borgia, io la detesto» (Donizetti 1978: 11). A Orsini ja l'havia advertit un vell vestit de negre «Fuggite i Borgia [...] dov'è Lucrezia è morte» (Donizetti 1978: 11) perquè «l'arti e il furor de' Borgia non ci potran colpir» (Donizetti 1978:12). De la unió de l'article i el cognom sorgeix l'expressió despectiva i amenaçadora en la qual Lucrècia s'autoafirma quan apareix al palau Negroni per anunciar la seua venjança: «Si, son la Borgia», assumpció del paper ingrat que l'entorn familiar li ha adjudicat. El duc també usa l'expressió «Vin d' Borgia» per a referir-se al vi enverinat. I Gennaro, abans de morir, repetirà incrèdul que «Sono un Borgia!».

\section{La paròdia}

Com havíem avançat, la popularitat del drama d'Hugo també suscita paròdies. «Cette toile macabre peinte au couteau par Hugo», com Ledda (2006) defineix Lucrèce Borgia, va inspirar Trigresse mortaux-rats ou poison et contre-poison, signat amb el pseudònim Dupin et Jules. Una «médecine en quatre- 
doses», com anomena cada acte, estrenada al Théatre des Varietés vint dies després del drama d'Hugo. Manté l'argument, però canvia el context de l'obra: Leduc ${ }^{10}$ i Tigresse Mort-aux-rates ${ }^{11}$ pateixen l'ofensa de Cascaro $^{12}$, qui retira tres lletres ${ }^{13}$ del rètol de la farmàcia que regenten a Bagnolet, un suburbi parisenc, amb la qual cosa «Gran Salomon Leduc, épicier-droguiste» esdevé «Grand Salo, Leduc, épicier-droguiste». La burla indigna Tigresse perquè «de cet mot raccourci, sans être bien malin / on devine aisement quel est le féminin» (Dupin 1833:18). Capturen Cascaro com en l'obra d'Hugo, però no per a matar-lo, sinó per a experimentar amb ell.

Tigresse és tan cèlebre pels nombrosos amants com el marit pels medicaments. Heus ací el verí i la luxúria: «C’est une femme enfin coquette et sanguinaire» (Dupin 1833:10), ens dirà Cascaro. Les propietats dels verins que descriu Hugo es porten al sarcasme: «Au berceau les enfans expirent de vieillesse, / parce que leurs mamans on trinqué chez Trigresse». Pel que fa a la luxúria, segons els jocrisse $^{14}$, com anomena els companys de Cascaro:

Elle aima son papa bien plus qu'il n'est permis,

Ses frères... tout enfin, excepté ses maris;

Et cet hereux chaos d'incestes, d'adultère,

Forme un piquant gâchis, où le fils est le père,

Où le père est le fils, où, grace à ses exploits,

La mère est fille et soeur, nièce et tante à la fois!

$[\ldots]$

Et, voulant désigner sur-le champ son espèce,

Son parrain lui donna le surnom de Tigresse (Dupin 1833: 5).

El millor resum, òbviament paròdic, del personatge creat per Hugo el facilita Cascaro:

Toi! C'est une amalgame

de panthères, de chat, d'ours, autant que de femme.

L'infant avec ton père est ton péché mignon,

l'inceste avec ton frère aussi t'a semblé bon;

tes cosins, tes neveux, tous tu les subtilises;

même avec tes enfants tu ferais des bêtises,

si les monstres avaient des enfants!... (Dupin 1833: 30)

L'obra apel la constantment a l'autoparòdia, com quan un jocrisse afirma de bell antuvi que «chacun devine ici quelle fut sa maman, / mais on n'en a pas l'air jusques au déneûment» (Dupin 1833: 5) tot ironitzant amb la previsibilitat del final. O quan Tigresse llig una carta de la mare anònima de Cascaro, el qual li retrau que: «Vous ne le lisez pas, vous le déclamez» (Dupin 1833: 9) i aquella respon que: «C’est que j’ai quelquefois joué la tragédie» (Dupin 1833: 9).

10 «marchand épicier-droguiste-apothicaire à Bagnolet (le Duc de Ferrare)» (Dupin 1833: 2).

11 «sa femme (Lucrèce Borgia)» (Dupin 1833: 2).

12 «jeune, conscrit, enfant privé de père et de mère (Gennaro)» (Dupin 1833: 2).

13 L'amputació de lletres també és objecte de burla en l'altra paròdia sobre Lucrèce Borgia, L'Ogresse Gorgia (Ubersfeld, 2001). Posada en escena a l'Ambigu-Comique l'endemà de Trigresse, Lucrècia és la dona d'un comerciant de papers pintats i el seu Marchand de bordures esdevé d'ordures [fem].

14 «Benêt ridicule qui se laisse mener par le premier venı» segons el Larousse.

SCRIPTA, Revista internacional de literatura i cultura medieval i moderna, núm. 6 / desembre 2015 / pp. 100 - 119 
La versemblança de l'argument d'Hugo és objecte de burla: «A croire ces messieurs, on ne voit dans les rues / que des enfants trouvés et des femmes perdues» (Dupin 1833: 6) proclama Grosbêta, el Gubetta de Lucrèce Borgia. Anomenar bèstia grossa al personatge que aporta els tocs còmics a l'obra transmet clarament el parer dels autors sobre l'humor d'Hugo.

A diferència de Lucrècia, Tigresse apareix a cara descoberta i es posa la màscara quan es descobreix la seua identitat. Això no evita que els jocrisse avisen que la insultaran i Cascaro afija una indirecta sobre l'excés de dramatisme en Hugo: «Il est deux choses qui ne s'arrachent jamais / sans faire frissonner et crier [...] La masque d'un femme. Et le dent d'un grand homme!» (Dupin, 1833: 10).

El llarg diàleg en què Tigresse intenta que el marit allibere Cascaro porta el romanticisme amorós a l'exageració:

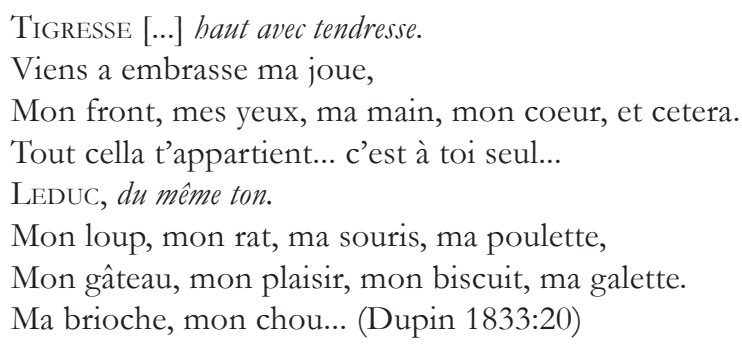

A banda d'un repàs privilegiat pels grans èxits de la música escènica francesa, Tigresse inclou cançons populars com la que obri la segona «dosi» J'arrive à pied de province o del folklore popular com la complainte de Fualdès que, interpretada amb orguenet, servirà per a acompanyar els càntics dels monjos d'Hugo, transformats ací en «file d'hommes vêtus de blouses; ils on chacun un rat-de-cave à la main» (Dupin 1833: 27). Els càntics, que qualifiquen Tigresse de susceptible, fan entendre la desproporció de la venjança davant de l'ofensa: tancar-los en cinc tonells de cervesa en contrast amb els taüts i el vi d'Hugo. La mateixa Tigresse reconeix que «tant de bière, je crois, ne manque pas d'effet: Voilà comme un auteur fait mousser un succès» (Dupin 1833: 28).

El desenllaç de l'obra es veu interromput pel xiulet d'un actor assegut a la platea, Monsieur Gigomart, fart d'escoltar els retrets de Cascaro a Tigresse, qualifica d'infame la funció, d'absurd l'argument i demana a la seua dona marxar, però Madame Gigomart replica que és d'allò més normal tenir un fill fora del matrimoni quan no estima el seu marit. Un altre membre del públic sol licita aleshores als actors que continuen perquè es tracta d'un «ouvrage charmant! Un tableau de moeurs délicieux! La peinturé fidèle de la societé!» (Dupin 1833: 33).

La dona de Gigomart travessa la quarta paret, prèviament tombada pel marit, i puja a l'escenari. Assedegada, beu d'un dels gots abans d'adonar-se que s'ha begut el verí. El marit la tranquil litza perquè com a màxim serà llimonada ja què «d'allieurs les drogues de messieurs les auteurs ne tuent que d'ennui... tout le monde en revient», excepte «le public qui ne revient pas» (Dupin 1833: 34). 
Mentre el marit marxa indignat els actors canten vítols al verí, la daga, l'incest i l'atrocitat. Cascaro afirma que, mentre les perruques dels crítics trauen foc i flames per a impedir els drames moderns dels joves autors, el que caldria són més obres semblants perquè el públic es fartara abans; una proclama profètica sobre l'avenir dels drames romàntics a partir de l'èxit comercial de la Comédie Française a mitjan dècada.

D'entre els nombrosos atacs a l'obra d'Hugo el més explícit i significatiu éstà al final de la cinquena escena de la tercera «dosi» quan Leduc marxa «sans vous dire pourquoi» (Dupin 1833:23) després d'arrancar el full d'un manuscrit on es llig amb grans caràcters «Lucrèce Borgia».

\section{Conclusions}

Com al drama d'Hugo, els companys del protagonista retrauen a Tigresse els seus crims: «Mon oncle $[. .$.$] y fut assassiné par ton style insipide [...] A mon père un jour [...] tu brisas la mâchoire en le$ faisant bâiller [...] mes deux tantes sont encore malades / pour avoir entendu tes maudites malades» (Dupin 1833: 11), uns crims més referits a Hugo que a Lucrècia, amb qui la relacionen a través del verí «empoisonnent déjà tous les coins de Paris [...] D'incestes, de forfaits tu parais idolâtre; ta maison, d'adultère est le honteux théâtre» (Dupin 1833: 11); és a dir, com els autors enverinen amb sensacionalisme la societat.

Hugo no només enverina els espectadors de l'època amb el seu teatre, com denuncia la paròdia, sinó també el personatge històric de Lucrècia Borja. L’èxit i la popularitat del drama com també els de l'òpera derivada uneixen la figura de Lucrècia Borja al punyal i al verí; una femme fatale allunyada de la imatge de princesa ideal que donen d'ella alguns contemporanis com Ariosto o del record que es guarda a Ferrara.

En el drama d’Hugo i els seus derivats operístics i paròdics Lucrècia mata per voluntat pròpia o obligada pel marit a conseqüència de la gelosia que sent cap al fill secret de Lucrècia. Gelosia provocada, no cal dir-ho, per la seua bellesa seductora i seduible. Si analitzem les obres de ficció no hi ha cap dubte que el personatge històric que ha inspirat Lucrècia Borja és una dona amb irradiació fascinadora que en la literatura del huit-cents, com hem vist, posseeix uns poders diabòlics; l'abjecte del qual parlava Kristeva (1980). Les representacions s'emmarquen en l'associació tradicional entre dona i verí, de la qual seria la icona, junt amb la por al poder femení i l'associació entre el sexe i la mort.

A la fi s'assenta en l'imaginari popular una Lucrècia Borja que comparteix característiques amb Locusta, Jocasta, Circe o Messal lina i no amb la Lucrècia romana, com la celebren en més d'una ocasió els seus contemporanis; Santa Caterina d'Alexandria i Santa Bàrbara, com la fa pintar son pare al Vaticà; Flora, com la retrata el Veneto; o, fins i tot, Marozia de la qual es podía extraure la prefiguració. 
Ens trobem, en conclusió, davant d'un personatge històric arrossegat per la mala fama de la seua familia; fama que serveix al Romanticisme per a erigir la figura d'una dona fatal, bella i perillosa, dolça $\mathrm{i}$ ambiciosa, amb gran èxit $\mathrm{i}$ influència sobre tota la literatura posterior. Una dona real que passarà a ser més coneguda pel personatge de ficció que ha inspirat que per les pròpies obres $i$ accions, malgrat l'abundància de documents i testimonis.

A Lucrècia Borja, filla de la màxima autoritat religiosa del moment, el Papa Alexandre VI, se li atorguen tota una sèrie de característiques -bellesa i luxúria- i d'atributs -el verí i el punyal- que fan que esdevinga un mite atractiu fins i tot a la terra on troba les arrels la nissaga com mostra l'obreta de teatre de Francisco Xavier Godó. Una mala fama que travessa l'Atlàntic -el 1867 Buffalo Bill anomena Lucretia Borgia al seu rifle per la capacitat mortífera- de la que Campari se servira per a anunciar-se en 1928 (Annex 1). 
Marc Gomar Calatayud. La Lucrècia Borja de ficció en el drama d'Hugo i els seus derivats

\section{Annex I}

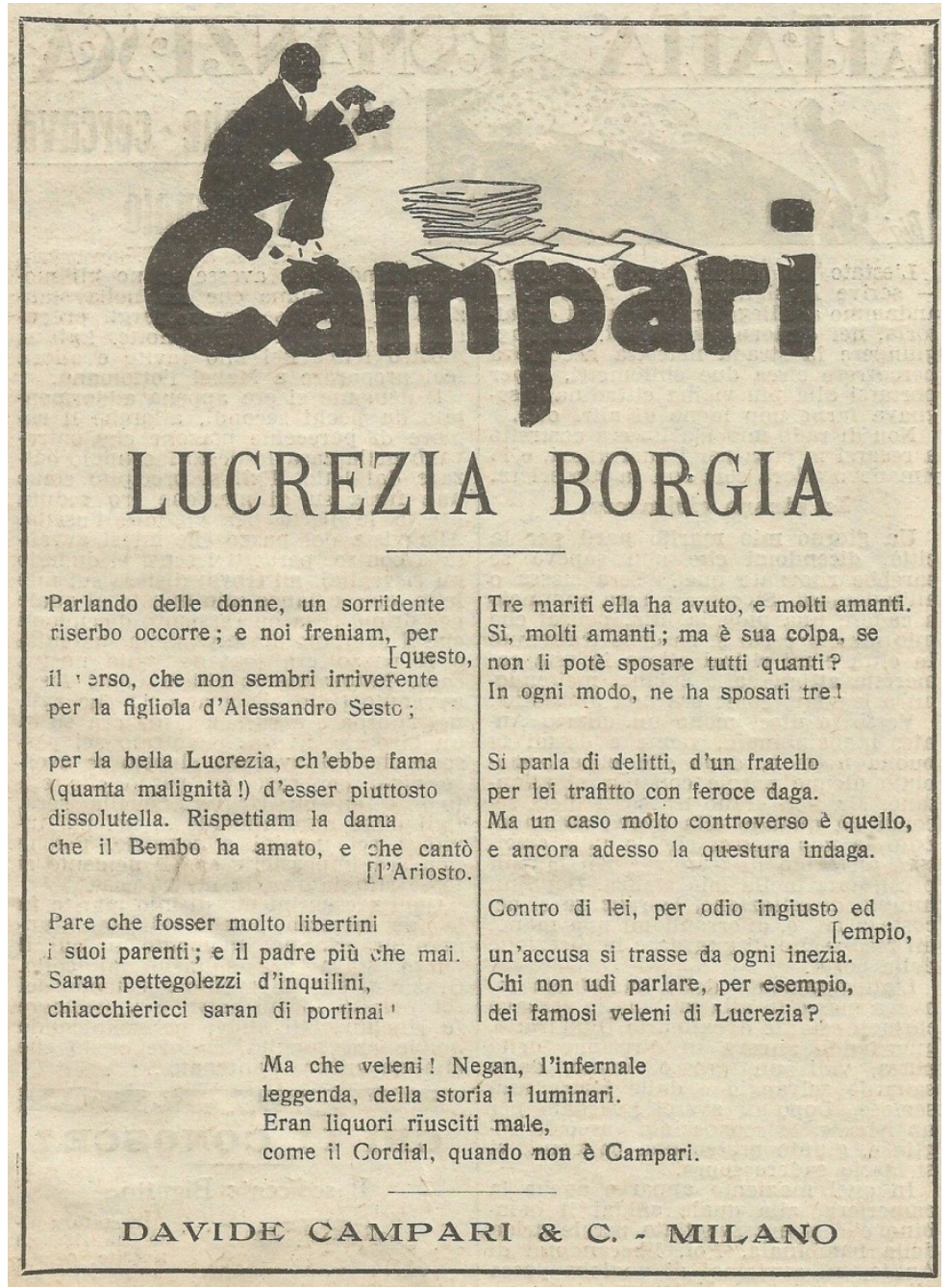

SCRIPTA, Revista internacional de literatura i cultura medieval i moderna, núm. 6 / desembre 2015 / pp. 100 - 119

ISSN: 2340-4841 · doi:10.7203/SCRIPTA.6.7825 


\section{Bibliografia}

Anònim (1816 / 1852) Romance de Lucrecia Borjia, Barcelona, Imprenta de Ignacio Estivill [http:/ / bdh-rd.bne.es / viewer.vm?id=0000097261\&page $=1]$

Anònim (1890) Gran Teatro del Liceo. Temporada de primavera 1890, Barcelona, imprenta de Jaime Jepús [

Branca, E. (1882) Felice Romani ed $i$ più riputati maestri di musica del suo tempo. Cenni biografici ed aneddotici, Torino-Firenze-Roma, Ermano Loescher [https://archive.org/details/ feliceromaniedi00brangoog]

De Quincey, T. (1999) Del asesinato considerado como una de las bellas artes, Valencia, Editorial La Máscara.

Donizetti, G. \& Romani, F. (1979) Lucrezia Borgia, Londres, The Decca Record Company Limited.

Dupin et Jules (1833) Tigresse mort-aux-rates ou Poison et contre-poison, quatrième, dose, scènes 3 et 4, médecine en quatre doses, [Théatre des Variétés, 22 février 1833], Paris, Barba.

Gilbert, W. (1869) Lucrezia Borgia, duchess of Ferrara. A biography. Illustrated by rare and unpublished documents in two volums. Vol. I \& II, Londres, Hurst and Blackett Publishers, [https:/ /archive.org/ stream/lucreziaborgiad00borggoog\#page/n0/mode/2up]

Gregorovius, F. (1975) Lucrecia Borgia. Edició reservada al Circulo de Amigos de la Historia, Gèneve, Editions Ferni.

Godó, F. X. (1895) Lucrezia Borgia. Joguina en un acte escrtia en vers catalá, Barcelona, Biblioteca de «Lo Teatro Regional».

Hugo, V. (2010) Lucrècia Borja (introducció i versió de J. Cortés), Alzira, Bromera.

Kristeva, J. (1980) Pouvoirs de l'horreur, Paris, Éditions du Seuil.

Le Thiec, G. (2012) Los Borgia. Luces y sombras, Barcelona, Paidós.

Ledda, S. (2006) «Lucrèce Borgia et la représentation de la mort» en Groupe Hugo, communication du 23 de septembre 2006, París, Universite París 7 - Equipe 19è siècle, [http://groupugo.div.jussieu. fr/groupugo/06-09-23Ledda.htm]

López de Meneses, A. (1951) «Pliegos sueltos románticos. La Torre de Nesle, Catalina Howard, El Conde de Montecristo y Lucrecia Borgia en España» dins Bulletin Hispanique. Tome 53, $\mathrm{N}^{\circ}$ 2, p. 176-205.

May, T. (2011) Secrets \& Masks. Bel Canto as Drama in Lucrezia Borgia. San Francisco, San Francisco Opera.

Mittag, M. (2007) «The Obscure Subject of Desire: Lucretia Borgia in Nineteenth-Century Literature» en Gender Forum. An Internet Journal of Gender Studies Issue 18 [http://www.genderforum.org/ issues/gender-disgussed/the-obscure-subject-of-desire/].

SCRIPTA, Revista internacional de literatura i cultura medieval i moderna, núm. 6 / desembre 2015 / pp. 100 - 119 
Marc Gomar Calatayud. La Lucrècia Borja de ficció en el drama d'Hugo i els seus derivats

Schüller Piroli, S. (1994) «Lucrècia Borja en la llegenda demoníaca dels papes» en Afers. Fulls de recerca i pensament, 17, Catarroja, Editorial Afers, p. 141-144.

Shüppert, H. (1994) «Lucrècia Borja, Un ideal de dona del Renaixement?» en Afers. Fulls de recerca $i$ pensament, 17, Catarroja, Editorial Afers, p. 45-55.

Ubersfeld, A. (2001) Le Roi et le bouffon, essai sur le théâtre de Victor Hugo, París, Éditions José Corti.

Weinstock, H. (1963) «Donizetti and the World of Opera» en Italy, Paris and Vienna in the First Half of the Nineteenth Century, Nova York, Pantheon Books.

Zarri, G. (2007) «Il Rinascimento di Lucrezia Borgia» en Scienza\& \&olitica, 37, pp.63-75.

Zemon Davis, N. (1996) Donne ai margini: tres vite del XVII secolo, Roma-Bari, Editori Laterza.

SCRIPTA, Revista internacional de literatura i cultura medieval i moderna, núm. 6 / desembre 2015 / pp. 100 - 119 